Article

\title{
Asymmetry and Tightness of Lower Limb Muscles in Equestrian Athletes: Are They Predictors for Back Pain?
}

\author{
Antonio Cejudo ${ }^{1,2} \mathbb{D}$, Angélica Ginés-Díaz ${ }^{1,2, *}$ and Pilar Sainz de Baranda ${ }^{1,2}$ (I) \\ 1 Department of Physical Activity and Sport, Faculty of Sport Sciences, Regional Campus of International \\ Excellence "Campus Mare Nostrum", University of Murcia, C.P. 30720 San Javier, Murcia, Spain; \\ antonio.cejudo@um.es (A.C.); psainzdebaranda@um.es (P.S.d.B.) \\ 2 Sports and Musculoskeletal System Research Group (RAQUIS), Campus de San Javier, University of Murcia, \\ C.P. 30720 Murcia, Spain \\ * Correspondence: Mariaangelica.gines1@um.es; Tel.: +34-868-88-8824; Fax: +34-868-88-8672
}

Received: 29 September 2020; Accepted: 10 October 2020; Published: 14 October 2020

check for updates

\begin{abstract}
Athletes may suffer from low back pain (LBP). Some studies have considered restricted range of motion (ROM) as a risk factor for LBP in athletes; however, ROM has not been evaluated in equestrian athletes (EAs) with LBP. The aims of this research in EAs were (I) to analyze the relationship between lower limb ROM (tightness and asymmetry) and LBP and (II) to determine the reference values for lower limb ROM indicating high risk of LBP. Forty-three young (9-18 years old) EAs were voluntarily recruited in technical training camps. The EAs were assessed for 11 passive lower limb ROMs using the ROM-SPORT I Battery. LBP data were taken at the end of a 1-year period through a questionnaire. Binary logistic regression and receiver operating characteristic curves were calculated. Sixty-seven percent of EA had suffered LBP. Hip adduction (OR $=1.347$, medium; $p=0.015)$ and knee flexion $\left(\mathrm{OR}=1.109\right.$, small; $p=0.023$ ) were predictors of LBP in EAs. A hip adduction of $26^{\circ}$ and knee flexion of $128^{\circ}$ were found to be the optimal cutoff values for predictive screening of EAs at high risk of LBP.
\end{abstract}

Keywords: flexibility assessments; receiver operating characteristic curves; ROM-SPORT I battery; risks factors for injury; spine pain

\section{Introduction}

Lower back pain (LBP) is a frequent symptom in equestrian athletes (EAs) that leads to innumerable missed competitions and training days [1]. EAs have higher LBP prevalence than the general population and other athletes [2-4], ranging from 20\% to 88\% [2-5]. Different risk factors have been associated to LBP in athletes such as muscle tightness [6-9], asymmetry [7,10-12], and sagittal spinal and pelvis misalignments [13-17].

Repetitive-stress loads of trainings place a high demand on the musculoskeletal system that leads to muscle tightness $[9,18,19]$. In the scientific literature, muscle tightness has been quantified by the range of movement (ROM) in cohort studies of sport injuries. Previous studies have determined different ROM cutoff values identifying injured athletes. Those athletes with ROMs lower than the ROM cutoff values (limited ROM) are classified as having muscle tightness. Several studies have shown that limited hip (extension $<13^{\circ}$ [20], adduction $<19^{\circ}$ [21], and flexion with knee extension $<70^{\circ}[22,23]$, knee (flexion $<132^{\circ}[10,20,24]$ ), and ankle (dorsiflexion $<45^{\circ}[25,26]$ ) ROM and asymmetry ROM are related to sports injuries affecting lower limbs. Moreover, restricted hip internal rotation $\operatorname{ROM}\left(<32^{\circ}\right)$ has been correlated to low back pain (LBP) in different athletes of rotation sport $[6,7,27]$. 
With regard to spinal misalignments, Auvinet [28] reported an incidence of lumbar hyperlordosis of $72 \%$ for professional EAs and Ginés-Díaz et al. [17] displayed hyperlordosis in standing position and hyperkyphosis in slump sitting and trunk flexion positions in EAs. The LBP is caused by high, repetitive, and multiplanar propulsion forces of the horse that are absorbed through the EA's body [29-31]. A misaligned spine increased and disproportionately distributed the mechanical forces transmitted by the horse to the pelvic hip complex and lumbar spine of rider $[17,19,31]$. When sitting, there is a loss of lumbar lordosis curvature and a posterior pelvis tilt. Due to this position, there is a compression of the anterior part of the intervertebral discs in the anterior part of the disc, and the fibrous ring and the nucleus migrate to a posterior position. All these phenomena induce injury to the intervertebral discs and enhance tension in the ligaments of the posterior part of the lumbar spine [32,33]. On the contrary, the anterior pelvic position and lordosis increases the compression of the posterior area of the intervertebral discs, the migration of the nucleus in this case is to the anterior position and the intradiscal pressure increases; the consequence of this compression is disc injury and increased tension affecting the ligaments of the anterior region of the spine [34,35].

Some studies reported a good correlation between hip and knee ROM and the sagittal disposition of the pelvis and lumbar curvature in EAs $[13,36,37]$. Show jumping riders displayed hip and knee flexion in the basic posture by the shortest use of the horse stirrup; this position allows the rider a greater impulse in the jump and a better cushioning in the horse landing after overcoming the obstacle $[1,36]$; however, this rider position causes pelvis retroversion and reduction of lumbar lordosis $[3,36]$. On the contrary, the use of horse stirrups with a longer length by dressage riders allows a more vertical position of the rider $[30,36]$. In this regard, Gandy et al. [13] suggested that the use of different lengths in the stirrups helps to adopt a pelvis and spine disposition within the normal ranges in EAs.

The key to reducing the risk of LBP is an adequate absorption and distribution of the different mechanical forces that the horse transmits to EAs' lumbo pelvic hip complex through the saddle [29,36]. One of the strategies to manage the forces generated by the horse is to accompany the different movements of the horse (walk, trot, canter, and gallop) by EAs with movements of posterior and anterior pelvic tilt while the rider keeps the spine aligned. Based on this knowledge, the EA requires adequate muscle extensibility to allow hip, pelvis, and lumbar spine mobility $[13,36]$. This mobility will allow the EA to adopt a neutral sagittal pelvic disposition and spinal alignment during riding $[17,19]$. Although the muscle extensibility is crucial to avoid LBP in EAs, this physical parameter has not yet been investigated.

Bearing all this in mind, the aims of this research in EAs were to determine whether lower limb flexibility (hip, knee. and ankle) and asymmetry measures are predisposing factors for LBP (I) and to perform a predictive LBP study to establish diagnostic cutoff values for those ROM associated with LBP (II). We hypothesized that a limited hip extension and flexion are correlated to LBP and may be predictors of LBP in EAs.

\section{Materials and Methods}

\subsection{Experimental Design}

This investigation was performed in EAs that have suffered $(n=13)$ or not $(n=29)$ from LBP during the last 12 months. This retrospective cohort study considered demographic data, training regime, anthropometric characters, and lower limb ROM as potential predictive factors for LBP in EAs. The assessment session was conducted in two regional level equestrian technical camps at the competitive sport season 2017/18. All testing was performed in the equestrian centers (Spain).

The recruitment of EAs was carried out the first day of the technical training camp. Both, the questionnaire (demographic, corporal composition, sport-related background, workout regimen, and history of LBP) and lower limb ROM were carried out the first two days of each regional technical training camp. Anthropometric characters (stature, body mass, body mass index, and body fat) and the 11 ROM tests of the main movements of the lower limb (dorsiflexion of ankle with flexed and 
extended knee; flexion of knee; hip extension; hip adduction with flexed hip; abduction of hip with flexed hip and hip at $0^{\circ}$; hip internal and external rotation; flexion of hip with extended knee and flexed knee were assessed by two experienced athletic trainers. All the EAs were asymptomatic in the assessment session.

This study was approved by the Ethics and Research Committee of the University of Murcia, Spain (ID: 1702/2017).

\subsection{Subjects}

Forty-three EAs (15 male and 28 female) with ages ranging from 9 to 18 years old were voluntarily recruited in a two regional technical training camps (Table 1). The participants competed in the modalities of classical dressage and show jumping. The formula "workout hours per day $\times$ workout days per week $\times$ four weeks per month $\times$ workout months per year" was used to calculate the training volume in the last 1-year $[9,38]$. The EA did realize any systematic and specific physical training plan in the last 1-year.

Table 1. Demographic and sport data of competitive 43 equestrian athletes.

\begin{tabular}{cccccc}
\hline Variable & Male $(\boldsymbol{n = 1 5 )}$ & Female $(\boldsymbol{n = 2 8 )}$ & $p$-Value & $\begin{array}{c}\text { Cohen's d } \\
\text { (Qualitative Inference) }\end{array}$ & Total $(n=43)$ \\
\hline Age (years) & $13.7 \pm 2.2$ & $14.4 \pm 2.1$ & 0.258 & -0.3279 (Small) & $14.2 \pm 2.1$ \\
Stature $(\mathrm{cm})$ & $160.4 \pm 14.5$ & $161.1 \pm 7.8$ & 0.740 & -0.0662 (Small) & $160.9 \pm 10.4$ \\
Body mass $(\mathrm{kg})$ & $54.8 \pm 13.0$ & $52.5 \pm 10.0$ & 0.460 & 0.2069 (Small) & $53.3 \pm 11.0$ \\
Body mass index $\left(\mathrm{kg} / \mathrm{m}^{2}\right)$ & $21.0 \pm 2.5$ & $20.1 \pm 3.1$ & 0.203 & $0.3094($ Small) & $20.4 \pm 2.9$ \\
$\quad$ Body fat $(\%)$ & $20.7 \pm 4.6$ & $24.9 \pm 6.5$ & 0.068 & -0.7094 (Small) & $23.5 \pm 6.2$ \\
$\begin{array}{c}\text { Riding experience } \\
\text { (years) }\end{array}$ & $6.5 \pm 2.3$ & $6.7 \pm 2.9$ & 0.671 & -0.0738 (Small) & $6.7 \pm 2.7$ \\
$\begin{array}{c}\text { Hours of training per } \\
\text { week (h) }\end{array}$ & $8.4 \pm 4.9$ & $7.4 \pm 5.8$ & 0.317 & 0.1815 (Small) & $7.7 \pm 5.5$ \\
$\begin{array}{c}\text { Training hours last } \\
\text { 12 month (h) }\end{array}$ & $402.5 \pm 235.6$ & $357.5 \pm 279.5$ & 0.317 & 0.1696 (Small) & $371.4 \pm 264.6$ \\
\hline
\end{tabular}

The EAs did not have orthopedic problems affecting the lower limb or spine in the last two weeks that could affect the EAs' movement competency, anthropometric characters, and lower limb range of motion (ROM).

Before participation, the parents/legal tutors and EAs completed a written informed consent, following the procedures set. The study was carried out according to the ethical standards of the Helsinki Declaration 1975. Participants were also informed that they were free to drop out of the study at any time. The power of the sample size for this study was analyzed as described in the Statistical Analysis section.

\subsection{Evaluators}

The data collection for this study were carried out by two evaluators. Evaluators were certified athletic trainers with at least 10 years of experience in musculoskeletal evaluation. All measurements of a specific parameter were always made by the same evaluators. Before the assessment procedure, a double-blind study was carried out (two testing sessions with $24 \mathrm{~h}$ apart) to establish the intraexaminer reliability with 12 athletes; the evaluators obtained an intraclass correlation coefficients greater than 0.88 (anthropometric traits: 0.98 to 0.99 ; hip, knee, and ankle ROMs: $0.90-0.96$ ) were obtained for all variables.

\subsection{Questionnaire}

Before the assessment session, EAs completed a questionnaire about their age, corporal composition (body mass, height, body mass index, and body fat percentage), sport-related background (equestrian sport modality, current competitive level, dominant-limb [leg used to kick the ball]) and systematic 
training workload (equestrian sport experience, days of training per week, and training hours per week). The information in the questionnaires was cross-referred with the coach and tutors in order to avoid subjectivity. The anthropometric measurements included in the questionnaire (stature, body mass, body mass index, and body fat) were assessed by the evaluators. Subsequently, EAs were asked if they had experienced LBP for longer than 1 week or whether they missed at least three days of training due to LBP [39] within the last 12 months. This information was used to determine the EA with previous history of LBP. Those EAs that experienced LBP during the sport practice or just after riding were also considered as EAs with history of LBP. The period of 1 week for lower back duration [8] was chosen to exclude simple "delayed onset muscle soreness" that may last for a few days. Similarly, all EAs with previous spine surgery were not included in this investigation.

\subsection{ROM-SPORT I Battery}

Eleven maximum passive hip $(n=8)$, knee $(n=1)$, and ankle $(n=2)$ ROMs were taken. The ROM assessment was performed according to the method previously described $[37,40]$. Figure 1 represents the maximum passive tests evaluated using the ROM-SPORT I battery [41,42]: dorsiflexion of ankle with flexed knee (ADF-KF) and extended knee (ADF-KE); flexion of knee (KF); hip extension (HE); hip adduction with flexed hip (HAD-HF); abduction of hip with flexed hip (HAB-HF) and hip at $0^{\circ}(\mathrm{HAB})$; hip internal (HIR) and external rotation (HER); flexion of hip with extended knee (HF-KE) and flexed knee (HF-KF) ROMs. Both, the non-dominant and the dominant lower limb were evaluated. The data related to hip total rotation (HTR) were calculated as the sum of the HER and HIR values.

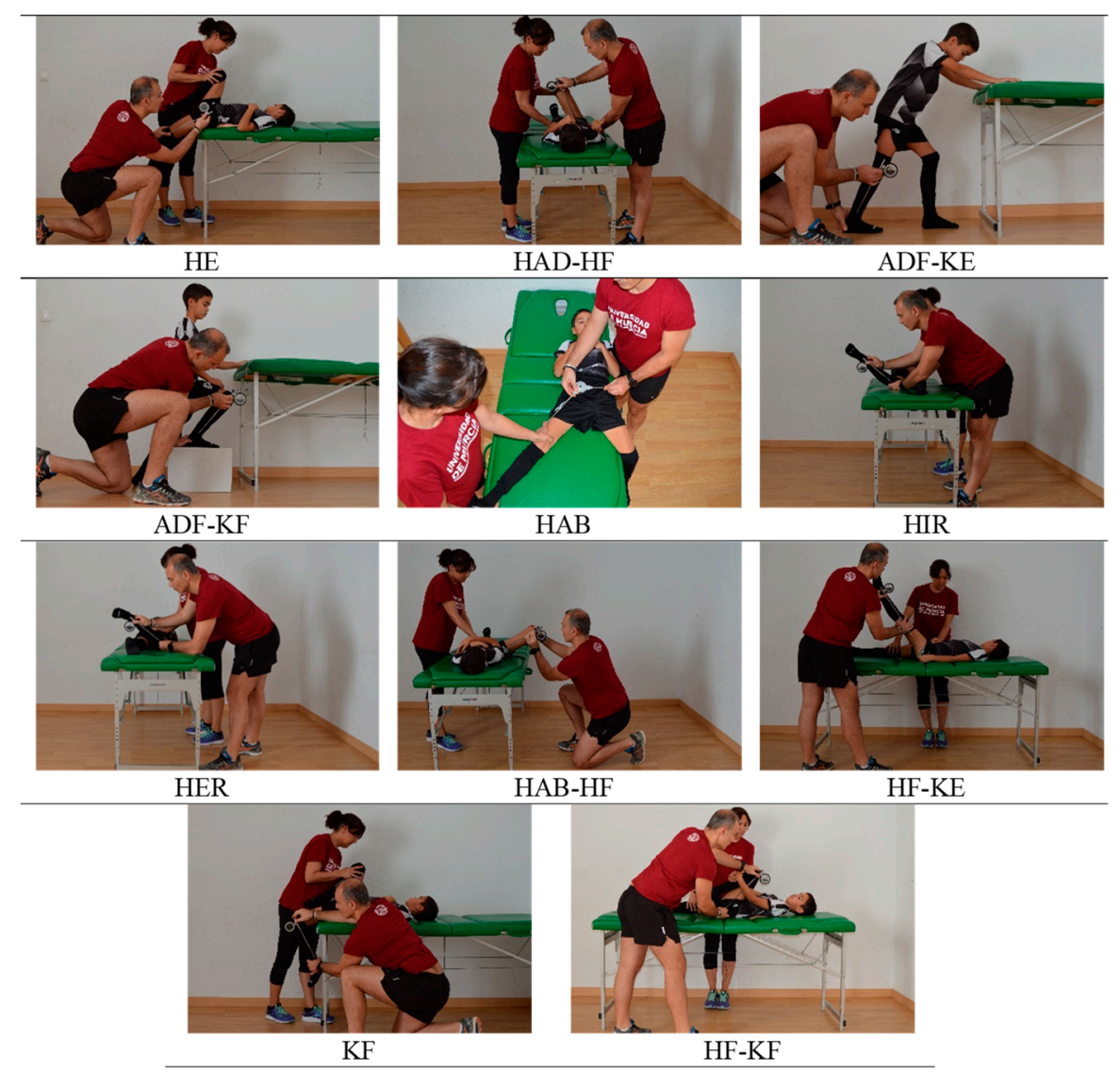

Figure 1. The range of movement tests of the ROM-SPORT I battery [41,42]: dorsiflexion of ankle with flexed (ADF-KF) and extended knee (ADF-KE); flexion of knee (KF); hip extension (HE); hip adduction with flexed hip (HAD-HF); abduction of hip with flexed hip (HAB-HF) and hip at $0^{\circ}$ (HAB); hip internal (HIR) and external rotation (HER); flexion of hip with extended knee (HF-KE) and flexed knee (HF-KF); ROM: range of motion. 
The ROM-SPORT I battery was used in this study because of its reliability $[40,43]$ and validity $[44,45]$ based on sport experience and biomechanical knowledge [46-49]. In addition, this battery follows the methodological principles of the international medical organizations. Previous investigations have described high to very high reliability (ranging from $4^{\circ}$ to $6.9^{\circ}$ ) for the different ROM tests [40,43].

In this study a familiarization session one week before the assessment session was performed. The aim of the familiarization session was to give to the EA all the information related to the technical execution of each ROM test. The ROM assessment was performed by two experienced evaluators under stable environmental conditions. All participants performed a dynamic warm-up, lasting approximately 15-20 $\mathrm{min}$, according to the recommendations of Taylor et al. [50] previous to the assessment session. After the warm-up, EAs performed two repetitions of each ROM test for each limb. The average score of each ROM value was employed for data analysis. The ROM tests were realized randomly. The EA rested $30 \mathrm{~s}$ between tests, lower limb, and repetitions.

Lower extremity ROMs of the hip and knee were assessed using an ISOMED Unilevel inclinometer (ISOMED, Inc, Portland, Oregon) [40]. The inclinometer was calibrated with the vertical or horizontal to $0^{\circ}$ either before the start of the assessment session. The angle between the longitudinal axis of the mobilized corporal limb (following its bisector) with the vertical or the horizontal was evaluated [40]. The hip abduction angle was evaluated with a metal goniometer (Baseline ${ }^{\circledR}$ Stainless) [43]. The lumbar lordosis was maintained at $20^{\circ}$ with the use of a lumbar support Lumbosant@ (Imucot Traumatología SL, Murcia, Spain) $[37,40]$. The end of each test was stablished according to at least one of these two conditions: (1) the athlete felt a strong muscle stretch without pain and/or the evaluators observed some compensatory movement that increased the ROM (2) [40].

\subsection{Statistical Analysis}

Data normality was investigated using the Shapiro-Wilk statistic and variance homogeneity between male vs. female was determined by Levene's test. All data showed an abnormal distribution.

The statistical analyses were carried out with the SPSS statistical package (SPSS Inc., Chicago, IL, USA). Data were expressed as means \pm standard deviations for all measured variables.

The independent sample of the Mann-Whitney U statistic was used to investigate differences according to sex in demographic variables and ROMs of the lower limb between. The Wilcoxon statistic was performed to study asymmetry between the dominant and non-dominant side. In addition, the Cohen's effect size was calculated for each ROM value. The effect size magnitude was classified according to Hopkins et al. [51] as extremely large (>4.0), very large (2.00 to 3.99), large (1.20 to 2.00), moderate $(0.6$ to 1.19$)$, small $(0.2$ to 0.59$)$, or trivial $(<0.2)$. Asymmetry was considered, when the effect size magnitude was moderated (minimum level of relevant effect with practical implementation [51,52]) or higher. The Mann-Whitney U statistic was used to compare continuous variables (age, corporal composition, sport-related background, systematic training workload, $11 \mathrm{ROMs}$, and $11 \mathrm{ROMs}$ asymmetry) between asymptomatic EAs (EA-A) and EAs with LBP (EA-LBP). The Hedges' g statistics were used to estimate the effect size of the variables.

Forward stepwise binary logistic regression models (probability $p \leq 0.05$, elimination probability $p \leq 0.10$ ) were used to identify variables associated with LBP; odds ratio analysis was used for calculating the simultaneous effects of several predictors instead of relative risk estimates [53]. Small effect (from 1 to 1.25), medium effect (from 1.25 to 2 ), and large effect ( $\geq 2)$ were the three categories used to interpret the effect sizes for the odds ratio (OR) [54].

The ROC (receiver operating characteristic) curves were used to determine optimal cutoff value for ROMs measured that identifies the EA more likely to suffer LBP. Area under the curve (AUC) ranges from 0.500 (not accurate to identify EA-LBP) to 1.000 (perfect accuracy to identify EA-LBP). The highest sensitivity (ability to detect the EA-LBP) and specificity (ability to detect the EA-A) were obtained at the optimal cutoff score estimated by the Youden index. This optimal cutoff score provides the best discriminating capacity between EA-A and EA-LBP. 
The relationship between the predictor-ROM classification (normal vs. limited according to optimal cutoff score) and LBP was calculated by Pearson's chi-squared statistic.

\section{Results}

The predictive variables obtained in this this study (Table 3 obtained a statistical power of 0.86 for HAD-HF, 0.61 for DTRF, and 0.81 for KF for 43 equestrian athletes [55].

Descriptive values of hip, knee, and ankle ROM parameters by limb dominance are shown in Table 2. Significantly higher values of HE, HAB, HIR, and HAB-HF were observed for the dominant limb compared to those recorded for the non-dominant limb in 43 EAs.

Table 2. Passive maximum lower limb range of motion values for the 43 equestrian athletes.

\begin{tabular}{ccccc}
\hline Variable & $\begin{array}{c}\text { Dominant } \\
\text { Side }\end{array}$ & $\begin{array}{c}\text { Non-Dominant } \\
\text { Side }\end{array}$ & $p$-Value & $\begin{array}{c}\text { Qualitative Inference } \\
\text { (Cohen's d) }\end{array}$ \\
\hline HE (iliopsoas) $\left(^{\circ}\right)$ & $12.4 \pm 5.4$ & $11.1 \pm 4.9$ & 0.010 & 0.252 (Small) \\
HAD-HF (abductors) $\left(^{\circ}\right)$ & $26.5 \pm 3.9$ & $27.1 \pm 3.4$ & 0.145 & -0.164 (Small) \\
DTRE (gastrocnemius) $\left(^{\circ}\right)$ & $34.1 \pm 4.4$ & $33.6 \pm 4.8$ & 0.281 & 0.108 (Small) \\
DFRF (soleus) $\left(^{\circ}\right)$ & $39.1 \pm 6.2$ & $39.5 \pm 5.6$ & 0.513 & -0.067 (Small) \\
HAB (adductors) $\left(^{\circ}\right)$ & $37.7 \pm 3.9$ & $36.3 \pm 3.7$ & 0.008 & 0.368 (Small) \\
HIR (external rotators) $\left(^{\circ}\right)$ & $53.8 \pm 9.3$ & $51.4 \pm 8.2$ & 0.001 & 0.273 (Small) \\
HER (internal rotators) $\left(^{\circ}\right)$ & $63.0 \pm 7.3$ & $63.7 \pm 6.8$ & 0.273 & -0.099 (Small) \\
HTR (hip rotators) $\left(^{\circ}\right)$ & $116.8 \pm 12.7$ & $115.1 \pm 11.1$ & 0.091 & 0.142 (Small) \\
HAB-HF (monoarticular & $63.3 \pm 8.9$ & $61.9 \pm 7.9$ & 0.017 & 0.166 (Small) \\
adductors) $\left(^{\circ}\right)$ & $69.7 \pm 7.0$ & $69.6 \pm 7.3$ & 0.819 & 0.014 (Small) \\
HF-KE (hamstring) $\left(^{\circ}\right)$ & $127.7 \pm 10.5$ & $127.0 \pm 10.2$ & 0.204 & 0.067 (Small) \\
KF (quadriceps) $\left({ }^{\circ}\right)$ & $135.3 \pm 6.0$ & $136.2 \pm 5.4$ & 0.192 & -0.1577 (Small) \\
HF-KF (gluteus maximus) $\left(^{\circ}\right)$ &
\end{tabular}

BMI: body mass index; dorsiflexion of ankle with flexed (ADF-KF) and extended knee (ADF-KE); flexion of knee (KF); hip extension (HE); hip adduction with flexed hip (HAD-HF); abduction of hip with flexed hip (HAB-HF) and hip at $0^{\circ}$ (HAB); hip internal (HIR) and external rotation (HER); flexion of hip with extended knee (HF-KE) and flexed knee (HF-KF).

Of the 43 riders involved in this study, 29 EA had suffered LBP during the last 1-year and were considered as EA-LBP. EA-A had higher training volume during the period of study than EA-LBP similar (EA-A 484.0 training hours last 12 months vs. EA-LBP 326.4 training hours last 12 months; $p=0.148 ;$ Hedges' $\mathrm{g}=0.6051$, moderate effect sizes).

Differences effect size were observed between EA-LBP and EA-A for HAD-HF [EA-A $28.9^{\circ} \mathrm{vs.}$ EA-LBP $26.0^{\circ} ; p=0.015 ;$ Hedges $^{\prime} \mathrm{g}=0.937$, moderate effect sizes) and KF [EA-A 132.2 ${ }^{\circ}$ vs. EA-LBP $124.4^{\circ} ; p=0.025 ;$ Hedges' $^{\prime} \mathrm{g}=0.866$, moderate effect sizes) (Table 3$)$.

The analysis of logistic regression identified among all the factors stated in Table 3 two predictive factors (HAD-HF and KF) with high classification accuracy $(76 \%, 32 / 43)$ for EAs with an experience of LBP and asymptomatic ones (HAD-HF: sensibility $=97 \%$; specificity $=31 \%$; KF: sensibility $=93 \%$; specificity $=38 \%$ ). However, this model found causal relationships between predictive variables (HAD-HF: $p=0.15$; Hedges' g = 0.9376, moderate; and KF: $p=0.025 ;$ Hedges' g $=0.8669$, moderate) and previous history of LBP. Logistic regression analysis indicated that of the potential predictive factors for LBP of Table 4 entered into the model, HAD-HF and KF showed medium (OR $=1.347$, $95 \% \mathrm{CI}=0.583$ to $0.944, p=0.015)$ and small $(\mathrm{OR}=1.109,95 \% \mathrm{CI}=0.823$ to $0.986, p=0.023)$ predictors of previous history of LBP in the 29 EAs, respectively. Moreover, the study of the frequencies found $88 \%(15 / 17)$ of successful cases in the group of EA-LBP, these athletes were classified as having low HAD-HF (cutoff $\left.\leq 26^{\circ}\right) ; 86 \%(18 / 21)$ of successful cases in the group of EA-LBP were classified as having low KF (cutoff $\leq 128^{\circ}$ ). The rest of the possible predictors of LBP did not show significant relative risk $(p>0.05)$. 
Table 3. Differences between equestrian athletes with an experience of lower back pain (EA-LBP) and asymptomatic ones (EA-A) in relation to all the evaluated variables.

\begin{tabular}{|c|c|c|c|c|}
\hline Variable & $\begin{array}{l}\text { EA-A }+ \\
(n=13)\end{array}$ & $\begin{array}{l}\text { EA-LBP }{ }^{\dagger} \\
(n=29)\end{array}$ & $p$-Value & $\begin{array}{l}\text { Effect Sizes Hedges' g } \\
\text { (Qualitative Inference) }\end{array}$ \\
\hline Age (years) & $14.2 \pm 1.6$ & $14.3 \pm 2.3$ & 0.840 & -0.047 (Small) \\
\hline Body mass $(\mathrm{kg})$ & $52.9 \pm 7.6$ & $53.6 \pm 12.5$ & 0.775 & -0.062 (Small) \\
\hline Height $(\mathrm{cm})$ & $162.2 \pm 8.7$ & $160.8 \pm 11.0$ & 0.881 & 0.135 (Small) \\
\hline $\operatorname{BMI}\left(\mathrm{kg} / \mathrm{m}^{2}\right)$ & $20.0 \pm 1.7$ & $20.5 \pm 3.3$ & 0.615 & -0.171 (Small) \\
\hline Body-fat $(\%)$ & $11.9 \pm 3.7$ & $13.0 \pm 6.1$ & 0.626 & -0.200 (Small) \\
\hline Years of experience (y) & $6.9 \pm 2.5$ & $6.6 \pm 2.8$ & 0.604 & 0.111 (Small) \\
\hline Training hours per week (h) & $10.1 \pm 7.1$ & $6.8 \pm 4.6$ & 0.148 & 0.603 (Moderate) \\
\hline Training hours last 12 month (h) & $484.0 \pm 338.5$ & $326.4 \pm 219.6$ & 0.148 & 0.605 (Moderate) \\
\hline HE (iliopsoas) $\left(^{\circ}\right)$ & $13.5 \pm 5.3$ & $10.7 \pm 4.6$ & 0.067 & 0.580 (Small) \\
\hline HAD-HF (abductors) $\left(^{\circ}\right)$ & $28.9 \pm 3.3$ & $26.0 \pm 3.0$ & 0.015 & 0.937 (Moderate) \\
\hline DTRE (gastrocnemius) $\left(^{\circ}\right)$ & $35.5 \pm 4.7$ & $33.4 \pm 3.8$ & 0.224 & 0.513 (Small) \\
\hline DTRF (soleus) $\left(^{\circ}\right)$ & $41.9 \pm 5.0$ & $38.2 \pm 5.9$ & 0.062 & 0.655 (Moderate) \\
\hline HAB (adductors) $\left(^{\circ}\right)$ & $38.2 \pm 2.5$ & $36.4 \pm 3.8$ & 0.125 & 0.520 (Small) \\
\hline HIR (external rotators) $\left(^{\circ}\right)$ & $54.0 \pm 7.1$ & $52.2 \pm 9.3$ & 0.376 & 0.207 (Small) \\
\hline HER (internal rotators) $\left(^{\circ}\right)$ & $64.8 \pm 6.0$ & $63.2 \pm 6.8$ & 0.533 & 0.243 (Small) \\
\hline HTR (hip rotators) $\left(^{\circ}\right)$ & $118.8 \pm 10.2$ & $115.4 \pm 12.0$ & 0.270 & 0.296 (Small) \\
\hline $\begin{array}{l}\text { HAB-HF (monoarticular } \\
\text { adductors) }\left(^{\circ}\right)\end{array}$ & $66.0 \pm 7.9$ & $61.4 \pm 8.2$ & 0.130 & 0.567 (Small) \\
\hline HF-KE (hamstring) $\left(^{\circ}\right)$ & $70.6 \pm 6.8$ & $69.0 \pm 7.0$ & 0.512 & 0.231 (Small) \\
\hline $\mathrm{KF}$ (quadriceps) $\left(^{\circ}\right)$ & $132.2 \pm 7.7$ & $124.4 \pm 9.5$ & 0.025 & 0.866 (Moderate) \\
\hline HF-KF (gluteus maximus) $\left(^{\circ}\right)$ & $137.5 \pm 4.3$ & $135.0 \pm 5.8$ & 0.176 & 0.463 (Small) \\
\hline
\end{tabular}

${ }^{+}$Data are expressed as Mean \pm Standard Deviation; BMI: body mass index; dorsiflexion of ankle with flexed (ADF-KF) and extended knee (ADF-KE); flexion of knee (KF); hip extension (HE); hip adduction with flexed hip (HAD-HF); abduction of hip with flexed hip (HAB-HF) and hip at $0^{\circ}$ (HAB); hip internal (HIR) and external rotation (HER); flexion of hip with extended knee (HF-KE) and flexed knee (HF-KF).

Table 4. Logistic regression and relative frequencies outcomes for lower back pain in the 43 equestrian athletes.

\begin{tabular}{ccccccc}
\hline Risk Factors & \multicolumn{2}{c}{ History LBP Last 1-Year } & $\begin{array}{c}\text { Odd Ratio } \\
\text { (Relative Risk) }\end{array}$ & $\begin{array}{c}\text { Standard } \\
\text { Error }\end{array}$ & $\begin{array}{c}\text { 95\% Confidence } \\
\text { Interval }\end{array}$ & $p$-Value \\
\hline $\begin{array}{c}\text { HAD-HF } \\
>26^{\circ}\end{array}$ & $\begin{array}{c}\text { EA-A } \\
44 \%(11 / 25)\end{array}$ & $\begin{array}{c}\text { EA-LBP } \\
56 \%(14 / 25)\end{array}$ & $\begin{array}{c}1.347 \\
\text { Medium }\end{array}$ & 0.123 & 0.583 to 0.944 & 0.015 \\
$\leq 26^{\circ}$ & $12 \%(2 / 17)$ & $88 \%(15 / 17)$ & & & & \\
\hline KF & EA-A & EA-LBP & 1.109 & 0.046 & 0.823 to 0.986 & 0.023 \\
$>128^{\circ}$ & $48 \%(10 / 21)$ & $52 \%(11 / 21)$ & Small & & & \\
$\leq 128^{\circ}$ & $14 \%(3 / 21)$ & $86 \%(18 / 21)$ & & & & \\
\hline
\end{tabular}

EA-A: asymptomatic equestrian athletes; EA-LBP: equestrian athletes with a history of lower back pain; flexion of knee (KF); hip adduction with flexed hip (HAD-HF).

The predictive model for EA-LBP displayed a good accuracy for HAD-HF and KF [56]. HAD-HF (AUC $=74 \%, p=0.015$, standard error: $0.080,95 \%$ confidence interval: 0.580 to 0.892 ) and KF (AUC $=72 \%, p=0.025$, standard error: $0.081,95 \%$ confidence interval: 0.559 to 0.878 ) demonstrated a high precision of discriminating against EA-LBP (Figures 2 and 3). ROC curves determined limited HAD-HF $<26^{\circ}$ (sensibility $0.85 \%$ and $52 \%$ specificity) and limited $\mathrm{KF}<128^{\circ}$ (sensibility $77 \%$ and $41 \%$ specificity) as the optimal cutoff values for predicting LBP in EAs. 


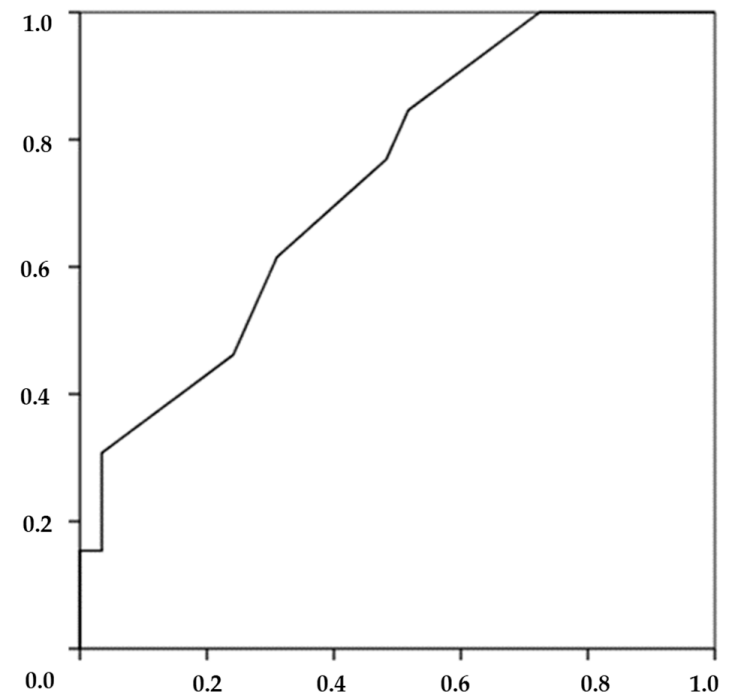

Figure 2. Representation of LBP probability for the hip adduction with hip adduction with flexed hip range of movement (optimal cutoff value $=26^{\circ}$; area under the curve $=74 \% ; p=0.015$ ) in equestrian athletes calculated based on the receiver operating characteristic curve statistic.

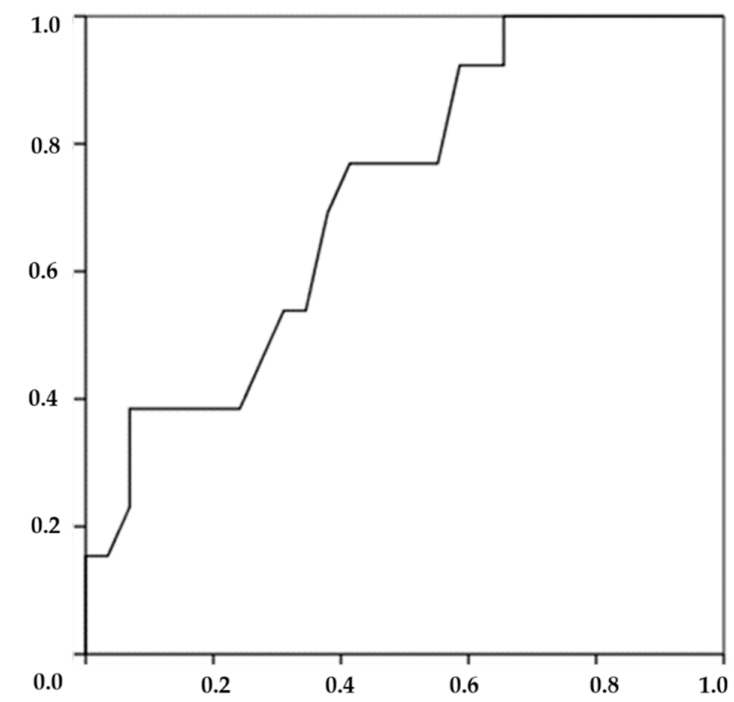

Figure 3. Representation of the LBP probability for the knee flexion range of movement (optimal cutoff value $=128^{\circ} ;$ area under the curve $=72 \% ; p=0.025$ ) in equestrian athletes calculated based on the receiver operating characteristic curve statistic.

Finally, the HAD-HF $\left(\leq 26^{\circ}\right)$ displayed a high statistical association with EA-LBP $\left(X^{2}{ }_{(42)}=4.920\right.$; $p=0.027 ; \eta 2=0.342$ ) resulting from the Pearson's chi-square statistic. The EA with limited HAD-HF $\left(\leq 26^{\circ}\right)$ had 5.9 times more probability to suffer LBP $(95 \% \mathrm{CI}=1.105$ to 31.412$)$ than an EA with a normal HAD-HF $\left(>26^{\circ}\right)$. The same statistical analysis showed that limited $K F\left(\leq 128^{\circ}\right)$ was highly associated with EA-LBP $\left(X^{2}\left({ }_{42}\right)=5.459 ; p=0.019 ; \eta 2=0.361\right)$. The EA with limited HAD-HF $\left(\leq 128^{\circ}\right)$ had 5.5 times more probability to suffer LBP $(95 \% \mathrm{CI}=1.226$ to 24.261$)$ than an EA with normal HAD-HF $\left(>128^{\circ}\right)$.

\section{Discussion}

According to our knowledge, this is the first report that determined the predictive ROM-related risk factors for LBP in EAs. The present investigation reports significant differences between EA-LBP and EA-A with respect to the percentage HAD-HF and KF. Interestingly, the EA-LBP had lower values in HAD-HF $(p=0.015)$ and KF $(p=0.025)$ than the EA-A. A HAD-HF and KF lower than $26^{\circ}$ and $128^{\circ}$, 
respectively, were identified as the main ROM variables for history of LBP in EA by regression model $(p \leq 0.023)$. These expected results are the most important findings of our research and will be very useful to decrease the incidence of LBP in EAs.

In present study a cutoff value of $26^{\circ}$ for HAD-HF was established; the EAs with values equal to or less than this value have a $74 \%$ of probability for developing LBP in the future. The transverse plane alignment mainly depends on the balance between the hip abductors muscle and adductor muscles [57-59]. Imbalanced muscles by muscle tightness, muscle asymmetry or weakness, cause pelvic transversal drop and functional lumbar lateral bending [57-59]. The overstressed lumbar soft tissue and facet joints is caused by lumbar spine lateral bending [60]. Any disturbance in function of these muscles can lead to LBP [60-62]. The only previous report determining a cutoff value of HAD-HF for an injury is that of L'Hermette et al. [21], which found that elite handball players with premature hip osteoarthritis showed an average of $19^{\circ}$ for HAD-HF. A prevalence of $81 \%$ for limited HAD-HF was found in this study. Similar prevalence data of limited HAD-HF by hip abductors tightness (from $65 \%$ to $88 \%$ ) has also been reported in young taekwondo athletes [63], elite inline hockey players [41,64], competitive futsal players [65-67], and competitive soccer players [42,68]. However, the effect of limited HAD-HF on LBP was not analyzed in those studies. Two studies have found an association between limited HAD-HF and increased of risk of LBP in athletes [69] and non-athlete populations [70], but they did not describe cutoff values of HAD-HF predicting LBP. Based on clinical experience, limited hip adduction ROM has been determined at a value equal to or less than $20^{\circ}[58,71], 30^{\circ}[46,47,72]$, $35^{\circ}$ [72], and $45^{\circ}$ [47], all these values do not have predictive validity for LBP since they are obtained from clinical experiences. On the contrary, the cutoff values reported in this study were established by a predictive study. Moreover, the HAD-HF values of the studies above are different from that described in this manuscript $\left(26^{\circ}\right)$, this fact is due to differences in the starting position, measuring instrument, measuring procedure, the criteria for the control of compensatory movements, and the criteria establishing the end of the test. These differences can significantly change the result of the HAD-HF value; for example, hip adduction with knee at $0^{\circ}$ decreases the result of the ROM (cutoff in $10^{\circ}$ for the modified Ober test) by limiting the tensor fasciae latae $[57,58]$. On the contrary, the resulting value of hip adduction increase (cutoff in $20^{\circ}-35^{\circ}$ for modified Ober test) if evaluators do not complete the test when a compensatory front rotation of the pelvis is observed $[47,72]$.

With respect to the KF, in present study a cutoff of $128^{\circ}$ was established. The probability of developing LBP for those EAs with KF values equal to or less than this cutoff is $72 \%$. The quadriceps are of primary importance in the athletes with LBP because they are powerful extensors of the knee and also a flexor of the hip; also, they have a direct influence on the position of pelvis and lumbar spine [73]. Marchall, Harrington, and Steele [74] and Kolber and Fiebert [73] stated that the permanent pelvic anteversion of the rider is caused by the tightness of hip flexors such as iliopsoas and quadriceps. The prevalence of limited KF in this study was $61 \%$. Higher values of prevalence for limited KF by hip quadriceps tightness (from $43 \%$ to $95 \%$ ) has also been reported in elite junior tennis [75], young taekwondo athletes [63], in elite inline hockey players [41,64], in distance runners [76], and professional soccer players $[10,20,42]$. However, the effect of limited KF (hip abductors tightness) on LBP has not been widely analyzed. In rotation-related sports, individuals with LBP revealed a lower KF that the asymptomatic ones [77]. Feldman, Shrier, Rossignol, and Abenhaim [78] found an association of LBP with limited KF and hamstrings tightness in adolescence students younger than 14 years. This is the first study demonstrating that limited KF is a risk factor for LB in EAs. These results are similar to those reported previously in other sports and injuries; some authors have reported reference values for KF for thigh strain in professional soccer players at values equal to or less than $121^{\circ}$ [24], $125^{\circ}$ for symptomatic patellofemoral pain syndrome in an athletic population, $132^{\circ}$ for thigh strain and sprained ankle in professional soccer players [20], and $110^{\circ}$ for overuse lower limb and sprained ankle in elite junior tennis [23]. Based on clinical experience, limited knee flexion was determined at values equal to or less than $125^{\circ}-130^{\circ}$ [71], $135^{\circ}$ [46,59], $140^{\circ}$ [72], 150 [47]. Although, these values are different to those reported in this study $\left(128^{\circ}\right)$, they do not have predictive validity for LBP since 
they are obtained from correlational studies or based on clinical experiences. The measurement of KF with hip flexion $[46,48,59,71]$ increases the ROM value of this movement; the same happens when measuring the knee flexion in prone position $[73,79]$. The KF procedure used in this study includes the movements (pelvic fixation in neutral position, hip at $0^{\circ}$ and knee flexion) opposite to all the quadriceps actions, while the assistant evaluator avoids compensatory movements. This is why the values obtained in our study are lower than those proposed by some clinical experts [46,47,59,71,72].

Riders adopt an external hip rotation position showing a larger ROM in the right limb "toe turn out" $[13,80]$; this position is caused by contraction of the posterior fascicles of the medius and minimus gluteus and abductors fascicles of major gluteus [81]. The contraction of these muscles result in hip abduction, extension, and external rotation [57] during horseback riding [81]. In addition, the external hip rotators tightness can also cause an increase hip external rotation [57,81]. Both muscles contraction as well as the muscle tightness immobilize the rider pelvis and interfere with the activity of horse's back muscles [13]. The lack of rider and horse coupling increases the transfer of mechanical forces and therefore the risk of LBP $[13,82]$.

In this sense, external rotation values higher than the reference values (general population $30-50^{\circ}$ vs. EA, $63.4^{\circ}$ ) have been observed in the EAs of this study $[46,47,59,71]$; however, the high values of external hip rotation of this study have not been associated to LBP. Cejudo et al. [9] reported that increased hip external rotation $\left(>56.5^{\circ}\right)$ predicted LBP in inline hockey players. These differences could be due to the specific technical movements of inline hockey, which require maximal external hip rotation during skating [9]. On the contrary, Van Dillen et al. [7] and Gombatto et al. [83] reported similar external rotation values to the general population and they observed similar values of external hip rotation between athletes with or without LBP.

Surprisingly, hip abduction and ankle dorsiflexion ROM were not associated with LBP. Hip adductors are responsible for stabilizing the rider's body on the horse, as well as establishing a unit connection between the two $[60,82]$. However, the results related to ADF-KF did not achieve the minimum level of significant effect for their practical implementation between EA with and without LBP in this study. This result was not expected because the surae triceps of EA, specifically in show jumping riders, are subjected to repetitive eccentric contractions caused by the permanent dorsi-flexion of ankle and the EA body mass. The cushioning of the mechanical forces of the horse performed by the EA lower limb minimizes the adsorption of these forces by the lumbar spinal $[80,81,84]$.

\section{Practical Guidelines}

A flexibility program should be part of the physical fitness plan for EAs. Those athletes with a high risk of injury due to a limited HAD-HF and KF or other ROM values, may perform a specific flexibility program to prevent LBP. In order to establish an adequate flexibility program, the evaluation of ROM (ROM-SPORT I battery) should be the first step to identify those EAs with muscle tightness. EAs, who do not exceed sport reference values, should also follow a flexibility program to increase muscle extensibility with special attention to quadriceps and hip abductors to prevent LBP and improve equestrian performance. Then, it is advisable to train the motor patterns as an adequate disposition of the pelvis and vertebrae column during horse gaits; as well as learning to minimize the mechanical forces generated by the horse. In addition, the use of different lengths in the stirrups is suggested for each equestrian discipline, longer length stirrups for dressage riders and shorter length stirrups for show jumping riders. The use of different lengths in the stirrups is also recommended to adopt an optima pelvis and spine disposition within the normal ranges by each EA.

\section{Conclusions}

This study demonstrated that hip adduction and knee flexion ROM are related with LBP in equestrian athletes. The $\mathrm{ROM}$ values of $26^{\circ}$ for hip adduction and at $128^{\circ}$ for knee flexion are the optimal cutoff values for predicting lower back pain in equestrian athletes in a screening evaluation. 
Author Contributions: Conceptualization, A.C., A.G.-D. and P.S.d.B.; methodology, A.C., A.G.-D. and P.S.d.B.; software, A.C.; validation, A.C., A.G.-D. and P.S.d.B.; formal analysis, A.C.; investigation, A.C., A.G.-D. and P.S.d.B.; resources, A.C.; data curation, A.C.; writing-original draft preparation, A.C.; writing-review and editing, A.C., A.G.-D. and P.S.B.; visualization, A.C.; supervision, P.S.d.B.; project administration, A.C. and P.S.d.B.; funding acquisition, A.C. and P.S.d.B. All authors have read and agreed to the published version of the manuscript.

Funding: This study is part of the project entitled "Study of risk of injury in young athletes through artificial intelligence networks" (DEP2017-88775-P), funded by the Spanish Ministry of Science and Innovation and Universities, the State Research Agency (AEI), and the European Regional Development Fund (ERDF).

Acknowledgments: We would like to thank all the staff of the Sports and Musculoskeletal System Research Group and to all the equestrian athletes who participated in this study.

Conflicts of Interest: The authors declare no conflict of interest.

\section{References}

1. Pugh, T.; Bolin, D. Overuse injuries in equestrian athletes. Overuse Inj. Equest. Athl. 2004, 3, $297-303$. [CrossRef]

2. Kraft, C.; Scharfstädt, A.; Yong, M.; Westhoff, B.; Urban, N.; Falkenhausen, M.; Pennekamp, P. Correlation of back pain and magnetic resonance imaging of the lumbar spine in elite horse vaulters. Sport. Sport. 2007, 21, 142-147. [CrossRef] [PubMed]

3. Kraft, C.N.; Pennekamp, P.H.; Becker, U.; Young, M.; Diedrich, O.; Lüring, C.; Von Falkenhausen, M. Magnetic resonance imaging findings of the lumbar spine in elite horseback riders: Correlations with Back pain, body mass index, trunk/leg-length coefficient, and riding discipline. Am. J. Sports Med. 2009, 37, 2205-2213. [CrossRef] [PubMed]

4. Pilato, M.; Shifrin, S.; Bixby-Hammett, D. The equestrian as an athlete: A view into injuries and incidence rates. Equest. Med. Saf. Assoc. Newsl. 2007, 1, 5-7.

5. Lewis, V.; Kennerley, R. A preliminary study to investigate the prevalence of pain in elite dressage riders during competition in the United Kingdom. Comp. Exerc. Physiol. 2017, 13, 259-263. [CrossRef]

6. Moreno-Pérez, V.; López-Valenciano, A.; Ayala, F.; Fernandez-Fernandez, J.; Vera-Garcia, F. Comparison of hip extension and rotation ranges of motion in young elite tennis players with and without history of low back pain. J. Back Musculoskelet. Rehabil. 2019, 32, 629-638. [CrossRef] [PubMed]

7. Van Dillen, L.; Bloom, N.; Gombatto, S.; Susco, T. Hip rotation range of motion in people with and without low back pain who participate in rotation-related sports. Phys. Ther. Sport 2008, 9, 72-81. [CrossRef]

8. Vad, V.; Bhat, A.; Basrai, D.; Gebeh, A.; Aspergren, D.; Andrews, J. Low Back Pain in Professional Golfers: The Role of Associated Hip and Low Back Range-of-Motion Deficits. Am. J. Sports Med. 2004, 32, 494-497. [CrossRef]

9. Cejudo, A.; Moreno-Alcaraz, V.J.; Izzo, R.; Santonja-Medina, F.; Sainz de Baranda, P. External and Total Hip Rotation Ranges of Motion Predispose to Low Back Pain in Elite Spanish Inline Hockey Players. Int. J. Environ. Res. Public Health 2020, 17, 4858. [CrossRef]

10. Fousekis, K.; Tsepis, E.; Poulmedis, P.; Athanasopoulos, S.; Vagenas, G. Intrinsic risk factors of non-contact quadriceps and hamstring strains in soccer: A prospective study of 100 professional players. Br. J. Sports Med. 2011, 45, 709-714. [CrossRef]

11. Cibulka, M.; Strube, M.; Meier, D.; Selsor, M.; Wheatley, C.; Wilson, N.; Irrgang, J. Symmetrical and asymmetrical hip rotation and its relationship to hip rotator muscle strength. Clin. Biomech. 2010, 25, 56-62. [CrossRef] [PubMed]

12. Ellenbecker, T.; Ellenbecker, G.; Roetert, E.; Silva, R.; Keuter, G.; Sperling, F. Descriptive profile of hip rotation range of motion in elite tennis players and professional baseball pitchers. Am. J. Sports Med. 2007, 35, 1371-1376. [CrossRef]

13. Gandy, E.A.; Bondi, A.; Pigott, T.; Smith, G.; Mcdonald, S. Measurement of hip flexion and pelvic rotation in horse riders using IMUs Investigation of the use of inertial sensing equipment for the measurement of hip flexion and pelvic rotation in horse riders. Comp. Exerc. Physiol. 2018, 14, 99-110. [CrossRef]

14. Harvey, J.; Tanner, S. Low back pain in young athletes. A practical approach. Sport. Med. 1991, 12, $394-406$. [CrossRef] [PubMed] 
15. Sadler, S.; Spink, M.; Ho, A.; De Jonge, X.; Chuter, V. Restriction in lateral bending range of motion, lumbar lordosis, and hamstring flexibility predicts the development of low back pain: A systematic review of prospective cohort studies. BMC Musculoskelet. Disord. 2017, 18, 179. [CrossRef]

16. Sainz de Baranda, P.; Cejudo, A.; Moreno-Alcaraz, V.; Martinez-Romero, M.; Aparicio-Sarmiento, A.; Santonja, F. Sagittal spinal morphotype assessment in 8 to 15 years old Inline Hockey players. PeerJ 2020, 8, e8229. [CrossRef]

17. Ginés-Díaz, A.; Martinez-Romero, M.; Cejudo, A.; Aparicio-Sarmiento, A.; Sainz de Baranda, P. Sagittal Spinal Morphotype Assessment in Dressage and Show Jumping Riders Physical. J. Sport Rehabil. 2019, 29, 533-540. [CrossRef]

18. McHugh, M.; Connolly, D.; Eston, R.; Gleim, G. Exercise-induced muscle damage and potential mechanisms for the repeated bout effect. Sport. Med. 1999, 27, 157-170. [CrossRef]

19. Hobbs, S.J.; Baxter, J.; Broom, L.; Rossell, L.-A.; Sinclair, J.; Clayton, H.M. Posture, Flexibility and Grip Strength in Horse Riders. J. Hum. Kinet. 2014, 42, 113-125. [CrossRef]

20. Ekstrand, J.; Gillquist, J. The frequency of muscle tightness and injuries in soccer players. Am. J. Sports Med. 1982, 10, 75-78. [CrossRef]

21. L'hermette, M.; Polle, G.; Tourny-Chollet, C.; L'hermette, M. Hip passive range of motion and frequency of radiographic hip osteoarthritis in former elite handball players. Br. J. Sport. Med. 2006, 40, 45-49. [CrossRef] [PubMed]

22. Okamura, S.; Wada, N.; Tazawa, M.; Sohmiya, M.; Ibe, Y.; Shimizu, T.; Usuda, S.; Shirakura, K. Injuries and disorders among young ice skaters: Relationship with generalized joint laxity and tightness. Open Access J. Sport. Med. 2014, 5, 191-195. [CrossRef] [PubMed]

23. Kibler, W.; McQueen, C. Fitness evaluations and fitness findings in competitive junior tennis players. Clin. Sports Med. 1988, 7, 403-416. [CrossRef]

24. Witvrouw, E.; Danneels, L.; Asselman, P.; D'Have, T.; Cambier, D. Muscle flexibility as a risk factor for developing muscle injuries in male professional soccer players: A prospective study. Am. J. Sports Med. 2003, 31, 41-46. [CrossRef]

25. Malliaras, P.; Cook, J.; Kent, P. Reduced ankle dorsiflexion range may increase the risk of patellar tendon injury among volleyball players. J. Sci. Med. Sport 2006, 9, 304-309. [CrossRef]

26. Backman, L.; Danielson, P. Low range of ankle dorsiflexion predisposes for patellar tendinopathy in junior elite basketball players: A 1-year prospective study. Am. J. Sports Med. 2011, 39, 2626-2633. [CrossRef]

27. Shah, S.; Testa, E.; Gammal, I.; Sullivan, J.; Gerland, R.; Goldstein, J.; Cohn, R. Hip Range of Motion: Which Plane of Motion Is More Predictive of Lower Extremity Injury in Elite Soccer Players? A Prospective Study. J. Surg. Orthop. Adv. 2019, 28, 201-208.

28. Auvinet, B. Lombalgies et équitation. Synoviale Rhumatol. Sport. 1999, 83, 25-31.

29. Humbert, C. L'équitation et Ses Conséquences sur le Rachis Lombaire du Cavalier: À Propos de 123 Observations; UHP-Université Henri Poincaré: Nancy, France, 2000.

30. Keener, M.; Johnson, E.; Dai, B. The Effect of Stirrup Length on Impact Attenuation and Its Association with Muscle Strength. J. Strength Cond. Res. 2020. [CrossRef]

31. Mason, C.; Greig, M. Lumbar Spine Loading During Dressage Riding. J. Sport Rehabil. 2020, $29,315-319$. [CrossRef]

32. Sainz De Baranda, P.; Cejudo, A.; Teresa Martínez-Romero, M.; Aparicio-Sarmiento, A.; Rodríguez-Ferrán, O.; Collazo-Diéguez, M.; Hurtado-Avilés, J.; Andújar, P.; Santonja-Medina, F. Sitting Posture, Sagittal Spinal Curvatures and Back Pain in 8 to 12-Year-Old Children from the Region of Murcia (Spain): ISQUIOS Programme. Int. J. Environ. Res. Public Heal. Artic. 2020, 17, 2578. [CrossRef] [PubMed]

33. Hedman, T.P.; Fernie, G.R. Mechanical response of the lumbar spine to seated postural loads. Spine 1997, 22, 734-743. [CrossRef] [PubMed]

34. Sainz de Baranda, P.; Andújar, P.; Collazo-Diéguez, M.; Pastor, A.; Santonja-Renedo, F.; Martínez-Romero, M.T.; Aparicio-Sarmiento, A.; Cejudo, A.; Rodríguez-Ferrán, O.; Santonja-Medina, F. Sagittal standing spinal alignment and back pain in 8 to 12-year-old children from the Region of Murcia, Spain: The ISQUIOS Program. J. Back Musculoskelet. Rehabil. 2020, 1-12. [CrossRef]

35. Pizones, J.; García-Rey, E. Pelvic motion the key to understanding spine-hip interaction. EFORT Open Rev. 2020, 5, 522-533. [CrossRef] 
36. Quinn, S.; Bird, S. Influence of saddle type upon the incidence of lower back pain in equestrian riders. Br. J. Sports Med. 1996, 30, 140-144. [CrossRef]

37. Santonja-Medina, F.; Santonja-Renedo, S.; Cejudo, A.; Ayala, F.; Ferrer, V.; Pastor, A.; Collazo-Diéguez, M.; Rodríguez-Ferrán, O.; Andújar, P.; Sainz de Baranda, P. Straight Leg Raise Test: Influence of LumbosantC and Assistant Examiner in Hip, Pelvis Tilt and Lumbar Lordosis. Symmetry 2020, 12, 927. [CrossRef]

38. Sainz de Baranda, P.; Santonja-Medina, F.; Rodríguez-Iniesta, M. Tiempo de entrenamiento y plano sagital del raquis en gimnastas de trampolín. Rev. Int. Med. Ciencias Act. Física Deport. 2010, 10, 521-536.

39. Trompeter, K.; Fett, D.; Platen, P. Prevalence of Back Pain in Sports: A Systematic Review of the Literature. Sport. Med. 2017, 47, 1183-1207. [CrossRef]

40. Cejudo, A.; Sainz de Baranda, P.; Ayala, F.; Santonja, F. Test-retest reliability of seven common clinical tests for assessing lower extremity muscle flexibility in futsal and handball players. Phys. Ther. Sport 2015, 16, 107-113. [CrossRef]

41. Cejudo, A.; Moreno-Alcaraz, V.J.; Croix, M.D.S.; Santonja-Medina, F.; de Baranda, P.S. Lower-Limb Flexibility Profile Analysis in Youth Competitive Inline Hockey Players. Int. J. Environ. Res. Public Health 2020, 17, 4338. [CrossRef]

42. Cejudo, A. El perfil óptimo de flexibilidad en jóvenes jugadores de fútbol durante su periodo sensible del desarrollo físico. Batería ROM-SPORT. JUMP 2020, 2, 16-25. [CrossRef]

43. Cejudo, A.; Ayala, F.; Sainz de Baranda, P.; Santonja, F. Reliability of two methods of clinical examination of the flexibility of the hip adductor muscles. Int. J. Sports Phys. Ther. 2015, 10, 976-983. [PubMed]

44. Enwemeka, C. Radiographic verification of knee goniometry. Scand. J. Rehabil. Med. 1986, 18, 47-49.

45. Gogia, P.; Braatz, J.; Rose, S.; Norton, B. Reliability and Validity of Goniometric Measurements at the Knee. Phys. Ther. 1987, 67, 192-195. [CrossRef]

46. Greene, W.; Heckman, J. Clinical Assessment of Joint Movement; Edika Med.: Barcelona, Spain, 1997.

47. Gerhardt, J.; Cocchiarella, L.; Lea, R. The Practical Guide to Range of Motion Assessment; American Medical Association: Chicago, IL, USA, 2002.

48. Norkin, C.; White, D. Measurement of Joint Motion: A Guide to Goniometry; FA Davis: Philadelphia, PA, USA, 2016; ISBN 9780803620667.

49. Magee, D. Orthopedic Physical Assessment; Elsevier Health Sciences: Philadelphia, PA, USA, 2013.

50. Taylor, K.; Sheppard, J.; Hamilton, L.; Plummer, N. Negative effect of static stretching restored when combined with a sport specific warm-up component. J. Sci. Med. Sport 2009, 12, 657-661. [CrossRef] [PubMed]

51. Hopkins, W.; Marshall, S.; Batterham, A.; Hanin, J. Progressive Statistics for Studies in Sports Medicine and Exercise Science. Med. Sci. Sport. Exerc. 2009, 41, 3-12. [CrossRef] [PubMed]

52. Hopkins, W. How to interpret changes in an athletic performance test. Sport Sci. 2004, 8, 1-7.

53. Fagerland, M.; Hosmer, D. A generalized Hosmer-Lemeshow goodness-of-fit test for multinomial logistic regression models. Stata J. 2012, 12, 447-453. [CrossRef]

54. Coombes, B.; Bisset, L.; Vicenzino, B. Efficacy and safety of corticosteroid injections and other injections for management of tendinopathy: A systematic review of randomised controlled trials. Lancet 2010, 376, 1751-1767. [CrossRef]

55. Faul, F.; Erdfelder, E.; Lang, A.; Buchner, A. G*Power 3: A flexible statistical power analysis program for the social, behavioral, and biomedical sciences. Behav. Res. Methods 2007, 39, 175-191. [CrossRef]

56. Cortes, C.; Mohri, M. AUC Optimization vs. Error Rate Minimization. Adv. Neural Inf. Process. Syst. 2004, 16, 313-320.

57. Kapandji, A. Fisiología Articular T2: Miembro Inferior; Médica Panamericana: Madrid, Spain, 2007.

58. Peterson, F.; Kendall, E.; Geise, P. Kendall's Músculos. Pruebas, Funciones y Dolor Postural; Marbán: Madrid, Spain, 2005.

59. Clarkson, H. Proceso Evaluativo Musculoesquelético: Amplitud del Movimiento Articular y Test Manual de Fuerza Muscular; Paidotribo: Barcelona, Spain, 2003.

60. Nourbakhsh, M.R.; Arab, A.M. Relationship between mechanical factors and incidence of low back pain. J. Orthop. Sports Phys. Ther. 2002, 32, 447-460. [CrossRef]

61. Purcell, L.; Micheli, L. Low back pain in young athletes. Sports Health 2009, 1, 212-222. [CrossRef] [PubMed]

62. Nadler, S.; Malanga, G.; Bartoli, L.; Feinberg, J.; Prybicien, M.; Deprince, M. Hip muscle imbalance and low back pain in athletes: Influence of core strengthening. Med. Sci. Sport. Exerc. 2002, 34, 9-16. [CrossRef] 
63. Cejudo Palomo, A.; San Cirilo-Soriano, B.; Robles Palazón, F.J.; Sainz de Baranda, P. Análisis del perfil de flexibilidad en jóvenes taekwondistas. Rev. Artes Marciales Asiáticas 2018, 11, 30-33. [CrossRef]

64. Cejudo, A.; Moreno-Alcaraz, V.J.; Izzo, R.; Robles-Palazón, F.J.; Sainz de Baranda, P.; Santonja-Medina, F. Flexibility in Spanish Elite Inline Hockey Players: Profile, Sex, Tightness and Asymmetry. Int. J. Environ. Res. Public Health 2020, 17, 3295. [CrossRef] [PubMed]

65. Sainz de Baranda, P.; Cejudo, A.; Ayala, F.; Santonja, F. Perfil óptimo de flexibilidad del miembro inferior en jugadoras de fútbol sala. Rev. Int. Med. Cienc. Act. Fis. Deport. 2015, 15, 647-662. [CrossRef]

66. Cejudo, A.; Robles-Palazón, F.; Sainz De Baranda, P. Fútbol sala de élite: Diferencias de flexibilidad según sexo. E Balonmano.com Rev. Cienc. Deport. 2019, 15, 37-48.

67. Cejudo, A.; Sainz de Baranda, P.; Ayala, F.; Santonja, F. Clasificación de los valores de rango de movimiento de la extremidad inferior en jugadores de fútbol sala. Sport TK Rev. Euroam. Cienc. Deport. 2017, 6, 41-50. [CrossRef]

68. Cejudo, A.; Robles-Palazón, F.; Ayala, F.; De Ste Croix, M.; Ortega-Toro, E.; Santonja, F.; Sainz de Baranda, P. Age-related differences in flexibility in soccer players 8-19 years old. PeerJ 2019, 2019, e6236. [CrossRef]

69. MacDonald, J. Back Pain in the Adolescent Athlete. Pediatr. Ann. 2007, 36, 703-712. [CrossRef]

70. Kukadia, H.A.; Malshikare, A.; Palekar, T.J. Effect of Passive Stretching v/s Myofascial Release in Improving Piriformis Flexibility in Females-A Comparative Study. Indian J. Physiother. Occup. Ther. 2019, $13,457$. [CrossRef]

71. Palmer, M.; Epler, M. Fundamentos de Las Técnicas de Evaluación Musculoesquelética; Paidotribo: Barcelona, Spain, 2002.

72. Gerhardt, J. Documentation of Joint Motion; Isomed: Portland, Oregon, 1994.

73. Kolber, M.; Fiebert, I. Addressing flexibility of the rectus femoris in the athlete with low back pain. Strength Cond. J. 2005, 27, 66-73. [CrossRef]

74. Marschall, M.; Harrington, A.C.; Steele, J.R. Effect of work station design on sitting posture in young children. Ergonomics 1995, 38, 1932-1940. [CrossRef]

75. Kibler, W. Strength and flexibility findings in anterior knee pain syndrome in athletes. Am. J. Sport. Med. 1987, 15, 49.

76. Duffey, M.; Martin, D.; Cannon, D.; Craven, T. Etiologic factors associated with anterior knee pain in distance runners. Med. Sci. Sports Exerc. 2000, 32, 1825-1832. [CrossRef]

77. Scholtes, S.; Gombatto, S.; Van Dillen, L. Differences in lumbopelvic motion between people with and people without low back pain during two lower limb movement tests. Clin. Biomech. 2009, 24, 7-12. [CrossRef]

78. Feldman, D.; Shrier, I.; Rossignol, M.; Abenhaim, L. Risk factors for the development of low back pain in adolescence. Am. J. Epidemiol. 2001, 154, 30-36. [CrossRef]

79. Kanchanomai, S.; Janwantanakul, P.; Pensri, P.; Jiamjarasrangsi, W. A prospective study of incidence and risk factors for the onset and persistence of low back pain in Thai university students. Asia Pac. J. Public Health 2015, 27, NP106-NP115. [CrossRef]

80. Byzova, A.; Roozbahani, H.; Handroos, H.; Hakansson, N.; Lankarani, H.M. Monitoring of the human body and brain behavior using optical motion capture system and EEG utilizing horseback riding simulator: An extended case study. J. Phys. Ther. Sci. 2020, 32, 85-91. [CrossRef]

81. Nicholson, N. Biomechanical Riding \& Dressage: A Rider's Atlas; Zip Publishing: Columbus, Ohio, 2006.

82. Symes, D.; Ellis, R. A preliminary study into rider asymmetry within equitation. Vet. J. 2009, 181, 34-37. [CrossRef]

83. Gombatto, S.; Collins, D.; Sahrmann, S.; Engsberg, J.; Van Dillen, L. Gender differences in pattern of hip and lumbopelvic rotation in people with low back pain. Clin. Biomech. 2006, 21, 263-271. [CrossRef]

84. Münz, A.; Eckardt, F.; Witte, K. Horse-rider interaction in dressage riding. Hum. Mov. Sci. 2014, 33, $227-237$. [CrossRef]

Publisher's Note: MDPI stays neutral with regard to jurisdictional claims in published maps and institutional affiliations. 